\title{
Prevalence of temporomandibular joint disorder symptoms in Cibodas Maribaya Village Bandung District
}

\author{
Erna Kurnikasari
}

Department of Prosthodontics Faculty of Dentistry Universitas Padjadjaran

\begin{abstract}
Temporomandibular joint disorder is a stomatognathic system disorder causing mandibular function disturbance that clinically shows the following symptoms: clicking, crepitation, limited mouth opening, pain in masticatory muscles, pain in jaw area, deviated mouth opening, ringing ear, pain around ear area, and headache. Experts stated that the prevalence of joint disorder was high. A study was conducted to the people of Cibodas Maribaya Village Bandung District who came to the Community Work event with results showing that the prevalence of clicking was 34 people or $32.4 \%$, the deviation was found in 36 people or $34.3 \%$, muscle pain was found in 28 people or $26.7 \%$, headache was found in 35 people or $33.3 \%$, ear disorders was found in 23 people or $21.9 \%$.
\end{abstract}

Key words: Temporomandibular joint disorder.

\section{INTRODUCTION}

Based on the definition from the American Academy of Orofacial Pain, temporomandibular joint disorder is a group of several clinical symptoms related to masticatory muscles, temporomandibular joint and its structures or combination of the two. ${ }^{1-3}$ The symptoms are vary and include, in general: joint sound (clicking), crepitation, limited mouth opening, tenderness or pain in masticatory muscles (myalgia), pain in the jaw joint area (arthralgia), deviated mouth opening, ringing ear (tinnitus), pain around the ear, and headache. ${ }^{1}$ An expert created a formula that a patient is diagnosed as having temporomandibular joint disorder if he or she experiences at least three of the symptoms. ${ }^{4}$

The causes of this disorder are complex and multifactorial which leads to arguments among experts. Several experts group the causes into three groups: predisposing factors, initiating factors, and perpetuating factors. $5,6,2,3$

Predisposing factors are factors that increase the risk for disorder that include systemic conditions such as rheumatoid, metabolism disorders, nutrition, hormone and infection and structural conditions such as occlusion disorder caused by missing posterior teeth, anterior open bite, overbite of more than 6-7 $\mathrm{mm}$ and unilateral crossbite as well as psychological disorders. Initiating factors are factors that trigger temporomandibular joint disorder that may be caused by excessive trauma and parafunctional habits.

The excessive trauma received by temporomandibular joint includes direct macrotrauma that causes sudden changes in structures related to the joint and microtrauma that causes indirect changes such as seen in people who do grinding and clenching. Perpetuating factors are etiological factors leading to delayed healing process that 
makes the disorder stays such as social behavior like receiving phone calls on the same ear, forward or bent head position while working, and emotional conditions like patient tends to be unable to control his/her emotion. An unpleasant working environment may cause someone to repeat his or her parafunctional habits that inhibit the healing process. $^{2,7}$ The prevalence of temporomandibular joint disorder is quite high in the community. Mardjono did the examinations to 739 students and found that $76 \%$ have one or more temporomandibular joint disorder symptoms. ${ }^{8}$ Meanwhile, in Jakarta the prevalence of temporomandibular joint disorder in adult is $79.3 \% .{ }^{9}$

\section{MATERIALS AND METHODS}

The type of study conducted was descriptive study and the sample selected were everyone who come to the health examination service during the Community Work event which was a collaboration among the Faculty of Dentistry, General Practitioners, Specialists and Dentists who are the alumni of Sekolah Menengah Atas Tiga (3 Senior High School) Bandung on 28 May 2008, in Cibodas, Maribaya Village, Bandung District. The total number of patients was 105, ranging from 1 to 61 years old, both males and females. The patients were given a questionnaire for personal data and questions, including: does the patient feel pain when opening and closing the mouth? Does patient often experience headache? Do the jaws feel rigid when getting up in the morning? On which side does the patient chew food? Has the patient's jaw experienced a bump? Has the patient ever experience disturbance on the ear?

Then a clinical examination on the joint disorder symptoms was performed to see the following symptoms: joint sound (clicking), jaw deviation (deviation), pain or tenderness of masticatory muscles, headache, disorders on the ear (tinnitus, hearing abnormalities, pain around ears), mouth opening width using three finger measurement, i.e. index finger, middle fingger and ring finger. If the mouth opening was less than three fingers, this shows a limited mouth opening. The instruments used in this study included: oral mirror, explorer, tweezers, stethoscope, rubber gloves, questionnaire and pen. When there were symptom/s seen, a plus (+) mark was assigned. When there was no symptom, a minus (-) sign was assigned. Then, all examination results were added up, made into a diagram and described.

\section{RESULTS AND DISCUSSION}

The study results can be reviewed in the Figure 1. Number of patients who experience clicking was 34 people or $32.4 \%$ of the total number of patients examined while those who did not experience clicking was 71 people, which was in line with a study performed by Goulet et al. ${ }^{10}$ and Magnussion in 2000. They said that clicking was found in $8-50 \%$ of the total sample. Number of patients who experience deviation was 36 people or $34.3 \%$ of the total number of patients examined, which was quite high because in Gale's study in $1992^{11}$, patients who experience jaw deviation is only $9.3-3.5 \%$. Number of patients who experience muscle pain is 28 people or $26.7 \%$, while in a study done by Riley and Gilbert ${ }^{12}$ in 2001 the prevalence of facial muscle pain and temporomandibular joint pain is around $5-15 \%$ showing that this study shows a higher prevalence. The number of patients who experience headache was 35 people or $33.3 \%$,

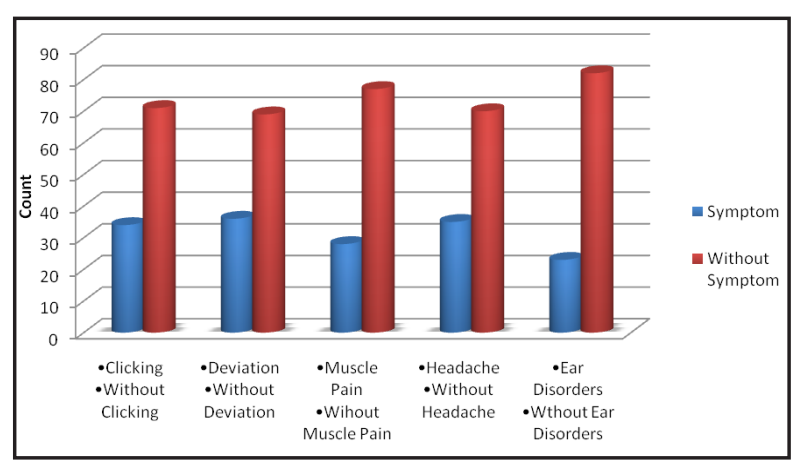

Figure 1. Number of patients who have various temporomandibular joint disorders.

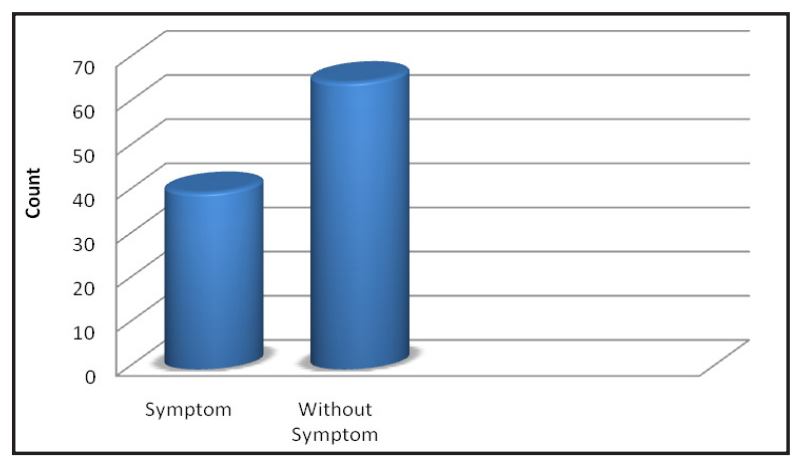

Figure 2. Number of patients with temporomandibular joint disorder. 
which is in accordance with the experts' statement that headache is the most common symptom that accompanies joint disorder. ${ }^{10}$ Furthermore, Costen in Carlsson and Magnusson, stated that seven out of eleven patients with joint disorder complain of headache.

Twenty three people or $21.9 \%$ of the patients experienced disorders in the ear that include tinnitus, i.e. ringing ear, feeling full in the ear, sometimes with disturbing sounds. The disorders in the ear had a quite high prevalence. All complaints showed high prevalence. This might be due to the fact that people in Cibodas Village didn't understand where and to whom they had to seek help and also this probably related to the low educational background. Almost all patients worked as farm workers with low economic level with all of them had never been examined for their complaint/s despite the fact that it was actually very disturbing.

From Figure 2 above, it could be observed that the prevalence of patients who have joint disorder symptom was 40 people out of 105 respondents who came or $38.09 \%$. This was quite high even though it was still lower than that in Mardjono's study, i.e. $79.3 \%$ and Solberg, i.e. $76 \%$.

\section{CONCLUSION}

Based on the study performed, respondents experience one or more symptoms of joint disorder so that it could be concluded that the highest frequency of temporomandibular joint disorder in the people of Cibodas Village who came for a treatment at the Community Work event were deviation, followed by headache, clicking, pain in masticatory muscles with ear pain as the least found disturbance. In this study, it was emphasized that the prevalence of temporomandibular joint disorder was still high so that careful management was still necessary.

\section{RECOMMENDATION}

Further study which is more detailed on temporomandibular joint disorder symptoms with bigger sample size is needed. It is necessary to do education to the community in rural area on factors that may cause temporomandibular joint disorder and how to handle it and where to seek help.

\section{REFERENCES}

1. Okeson JP. Management of temporomandibular disorders and occlusion. $6^{\text {th }}$ ed. St. Louis: CV. Mosby: Inc.; 2008.

2. Carlsson GE, Magnusson T. Management of temporomandibular disease in general dental practice. Chicago: Quintessence Publishing Co. Inc.; 1999. p. 19-23.

3. Coulthard P. Master dentistry oral and maxillofacial surgery, radiology, pathology and oral medicine. Philadelphia: Churchill Livingstone; 2003. p. 348-52.

4. Dawson PE. Evaluation, diagnosis and treatment of occlusal problem. St. Louis: C.V. Mosby Co.; 1974. p. 16-34.

5. Pertes RA, Gross SG. Clinical management of temporomandibular disorders and orofacial pain. Chicago: Quintessence Publishing Co. Inc.; 1995. p. 1-9.

6. Mc Neill C. Management of temporomandibular disorders: concept and controversies. J Prosthet Dent 1997;77:510-21.

7. Solberg WK, Woo MW. Houston JB. Prevalence of mandibular joint dysfunction in young adults. J Am Dent Ass 1980;98:25-33.

8. Mardjono D. Hubungan antara pola mengunyah kebiasaan yang salah dengan dysfungsi sendi temporomandibula pada orang dewasa di Jakarta. Dissertasion. Bandung: Universitas Padjadjaran; 1989. p. 65-68.

9. Sarnat BG, Laskin DM. The temporomandibular joint: A biological basis for clinical practice. $2^{\text {nd }}$ ed. Philadelphia: WB. Saunders Co.; 1992. p. 237-46.

10. Goulet. Investigating clicking sound. In: Bumann A, Lotzmann U. Temporomandibular joint disorders and orofacial pain: the role of dentistry in multidiscipline diagnostic approach. Stutgart: Thieme Pub; 2002. p. 98.

11. Gale. Epidemiology. In: Sarnat BG, Laskin DM. The temporomandibular joint: A biological basis for clinical practice. Philadelphia: W.B. Saunders. Co.; 1992. p. 237-55.

12. Riley, Gilbert. Facial pain and temporomandibular disorders 2001. [cited 20 Jul 2009]. Available from: http://www.hercules.oulu.fi. 